\title{
Wind Power Plant Modeling based on Grid Codes Requirements using Real-Time Digital Simulator
}

This paper was downloaded from TechRxiv (https://www.techrxiv.org).

LICENSE

CC BY 4.0

SUBMISSION DATE / POSTED DATE

$12-01-2022$ / 19-01-2022

CITATION

Nomandela, Sinawo (2022): Wind Power Plant Modeling based on Grid Codes Requirements using RealTime Digital Simulator. TechRxiv. Preprint. https://doi.org/10.36227/techrxiv.18277394.v1

DOI

10.36227/techrxiv.18277394.v1 


\title{
Wind Power Plant Modeling based on Grid Codes Requirements using Real-Time Digital Simulator
}

\author{
Sinawo Nomandela
}

\begin{abstract}
The load demand to the power grid, as well as the interest in clean and low-cost energy resources, leads to the high integration of wind power plants into the power system grid. Grid code standards were set for the design and integration of these wind power plants. These codes are often based on the design operation of the wind power plant in islanded mode, where possible analysis of the most sensitive power system quantities such as voltage, frequency, reactive power, etc. is done. Therefore, attention needs to be paid to the application of these codes to maintain the design and integration of wind power plants to keep their operation standardized as much as possible. The purpose of this research is to model and simulate in real-time the wind power plant while adhering to the grid code requirements.
\end{abstract}

Index Terms-Renewable Power Plant (RPP), South African Renewable Grid Code Standards (SAREGCS), Wind Power Plants (WPP), Wind Turbine, Wind Turbine Generator Unit (WTGU), Wind Turbine Power Coefficient $(C p)$, Grid compliance test, Voltage, Frequency.

\section{INTRODUCTION}

I $\mathrm{T}$ is believed that the traditional energy resources of power will vanish in the coming years. This will lead to a complete escape from the traditional power resources to renewable resources. Wind energy is the leading energy source. This is proven by the recorded data obtained from the worldwide gigawatt $(\mathrm{GW})$ installation [1], whose data show that the global estimated installed total capacity of wind power was $592 \mathrm{GW}$ in 2018.

One of the benefits of wind power plants (WPPs) is that they are located close to customers. WPPs can be operated in two modes, namely the grid-connected and standalone (islanded) mode, depending on the grid stability requirements. In the gridconnected mode, the WPPs contribute additional power when the load demand increases. In the islanded mode, they serve as an emergency supply for individual loads when the power supplied by the grid is insufficient. There are additional services for the conditions of a grid-connected mode, such as frequency and voltage adjustments, harmonic compensation, power backup, network stability, additional reserve, and clearing of load peaks [2].

One of the requirements in power system operation is to keep the power grid supply stable. There are control techniques used on the mechanical side of traditional generating stations to ensure the stability of the system under the conditions of power

Mr. Sinawo Nomandela is with the Center for Substation Automation and Energy Management Systems (CSAEMS) at the Cape Peninsula University of Technology, Bellville 7535 South Africa (email: nomandelas@cput.ac.za). system disturbances. However, their operation is limited when severe disturbances, such as sudden increases or decreases in load demand, occur in the system. In the case of an increase in load demand, additional power sources such as WPPs play a significant role.

Many studies have been conducted on the integration of wind power plants (WPPs) into power grids. However, research that considers WPPs in an islanded mode of operation is rare. In addition, some of the published work makes use of a single wind turbine generator unit (WTGU) and assumes that it is a complete WPP, as is supposed to consider the modeling of multiple WTGs to accommodate WPP dynamics at large.

To mention a few studies, [3] conducted a study of wind power plant integration into a weak distribution network. Their wind power plant model consists of a $6 \mathrm{MW}$ single wind turbine generator (WTG) model that is sufficiently large to represent a reasonable megawatt capacity of a wind power plant. A $9 \mathrm{MW}$ single WTG for integration into the grid through a static synchronous compensator (STATCOM) was modeled in [4]. Their results showed that the wind power plant could not stay connected to the grid without the use of STATCOM.

It is understood that the computation of each component consumes time. Wind speed is not the same in a wind-power plant area. This means that the power produced by each windturbine generator differs from one another. However, because there are many turbines in a wind power plant, the dynamic behavior of an individual wind turbine is canceled by the other. Thus, the results obtained in [4] may not be valid. The same applies to [3], and their model may not provide enough validation of their study. Additionally, none of these models were first run standalone for grid compliance tests, as the grid codes require. This violates the design requirements of wind power plants for grid integration, as mentioned in [5].

This paper looks at the wind power plant (WPP) modeling and testing on real-time simulation to ensure the minimum grid code compliancy.

\section{WIND POWER Plant MODELING}

The wind power plant considered in this study was modeled using the existing parameters from Vestas. The turbine drives a squirrel-cage induction generator whose parameters are adopted from published and recognized literature [6], [7].

This section describes the modeling of the wind turbine, 
$>$ REPLACE THIS LINE WITH YOUR MANUSCRIPT ID NUMBER (DOUBLE-CLICK HERE TO EDIT) <

squirrel-cage induction generator, wind turbine generator substation unit (WTGSU) transformer, transmission line modeling, and the wind power plant reactive power compensator.

\section{A. Wind Turbine Model}

The wind turbine generator requires a mechanical prime mover to produce electrical power. The Vestas V117-4.2 MW wind turbine is selected for this purpose and is modeled on the RSCAD, as shown in Fig. 1. It has three input signals written pitch (deg), wind speed $(\mathrm{km} / \mathrm{h})$, and speed $(\mathrm{pu})$. To obtain this wind turbine model, the parameters need to be set, and the mapping of control and calculation logics for these input signals is required. In this section, the setting of the wind turbine generator parameters, modeling of control, and calculation logic are described. Once these control and calculation logics are modeled, an output signal with the name torque $(\mathrm{pu})$ is coupled to a generator for the conversion of mechanical power to electrical power.

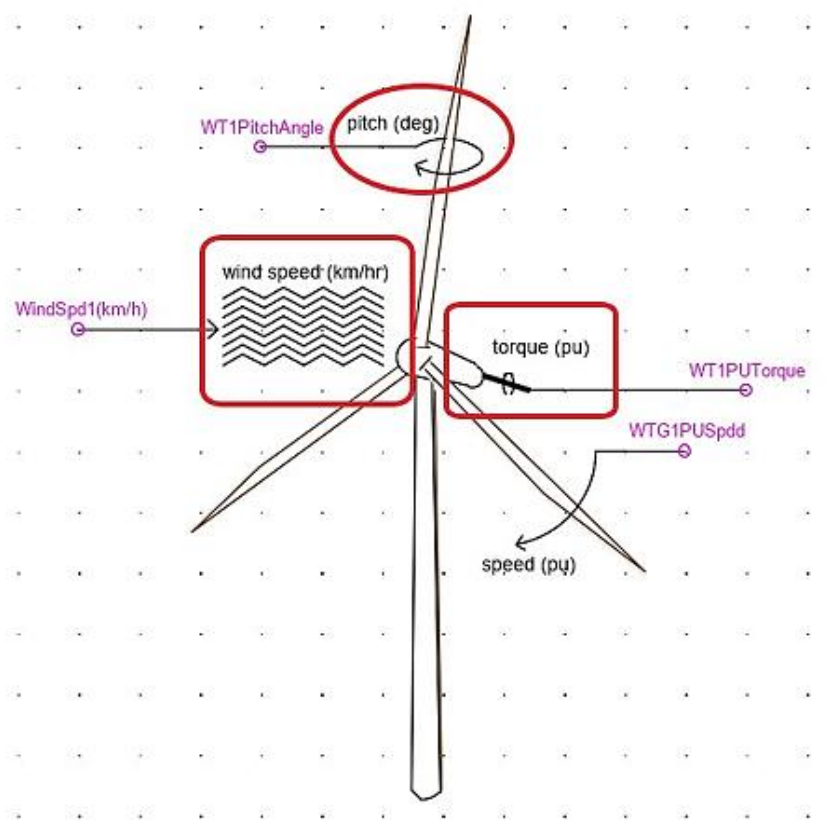

Fig. 1. RSCAD wind turbine model

\section{1) Wind Turbine Modeling}

The three inputs and one output, pitch (deg), wind speed $(\mathrm{km} / \mathrm{h})$, speed $(p u)$, and torque ( $p u)$ were defined as shown in Fig. 1. The signals named WindSpdl $(\mathrm{km} / \mathrm{h})$ and WTIPitchAngle are input signals from the wind speed and pitch angle adjustment components. WTGIPUSpdd is the feedback per unit speed signal from the driven generator. WTIPUTorque is the output per unit torque. This signal drives the generator to be coupled to the wind turbine.

Wind turbines convert approximately $40 \%$ to $48 \%$ of the power produced by the moving wind and transfer it to the generator rotor through a torque mechanism, wherein the later stage is converted to electrical power.

The percentage values stated above represent the efficiency of the wind turbine, which is referred to as the turbine power coefficient $\left(C_{p}\right)$.
Various equations exist for this parameter. However, the wind power plant model used in this study was based on the equation

$$
C_{p}=k_{1}\left(\lambda+k_{2} \beta^{2}+k_{3}\right) e^{k_{4} \lambda}
$$

where $\beta$ and $\lambda$ are the pitch angle adjustments of the wind turbine blades and the tip speed ratio of the wind turbine, respectively.

The tip speed ratio $(\lambda)$ is given by the following expression

$$
\lambda=\frac{\mathrm{v}_{\mathrm{W}}}{\mathrm{\omega}_{T R}}
$$

In the expression, $v_{W}$ and $\Phi_{T R}$ are the velocity of wind in meters per second $(\mathrm{m} / \mathrm{s})$ and rotational velocity of the turbine rotor in radians per second $(\mathrm{rad} / \mathrm{sec})$ respectively. The literature exists with different equations for the design of wind turbine efficiency $(C p)$. However, in this study, we considered Equation (1) because of some difficulties in RSCAD to define several constants specified for some of the equations.

The constants in Eq. (1) have the values $k_{1}, k_{2}, k_{3}$ and $k_{4}$

\begin{tabular}{|c|c|c|c|c|c|c|c|}
\hline \multicolumn{8}{|c|}{ Itds_windturbine.def } \\
\hline \multicolumn{3}{|c|}{ GENERATOR PARAMETERS } & MONITORING & \multicolumn{4}{|c|}{ SIGNAL NAMES } \\
\hline \multicolumn{2}{|c|}{ CONFIGURATION } & \multicolumn{2}{|c|}{ TURBINE PARAMETERS } & \multicolumn{3}{|c|}{ Atmospheric Conditions } & Cp Constants \\
\hline Name & \multicolumn{3}{|c|}{ Description } & Value & Unit & Min & Max \\
\hline k1 & \multicolumn{3}{|l|}{ Constant k1 } & 0.5 & & & \\
\hline k2 & \multicolumn{3}{|l|}{ Constant k2 } & -0.022 & & & \\
\hline k3 & \multicolumn{3}{|l|}{ Constant k3 } & -5.6 & & & \\
\hline k4 & \multicolumn{3}{|l|}{ Constant k4 } & -0.17 & & -10.0 & 0.0 \\
\hline note & \multicolumn{3}{|c|}{$C p=k 1\left(g a m m a-k 2^{*} \text { pitch }{ }^{\star \star} 2-k 3\right)^{*} \exp \left(k 4^{*}\right.$ gamma $)$} & 0 & & & \\
\hline $\operatorname{gmin}$ & \multicolumn{3}{|c|}{ Gamma Range minimum limit } & 0.001 & & 0.0 & 100.0 \\
\hline$g \max$ & \multicolumn{3}{|c|}{ Gamma Range maximum limit } & 60.0 & & 0.0 & 100.0 \\
\hline \multirow[t]{2}{*}{ Cpmin } & \multicolumn{3}{|c|}{ Minimum Limit of $\mathrm{Cp}$} & -0.1 & & -0.593 & 0.0 \\
\hline & & & Cancel & Cancel A & & & \\
\hline
\end{tabular}
and were set as shown in Fig. 2.

Fig. 2. Power coefficient $(\mathrm{Cp})$ parameters of the wind turbine

\section{2) Wind Turbine Modeling}

The wind turbine generator model in this study has a turbine rotor rotational speed of 9.9 RPM at nominal, and the induction generator shaft requires thousands of RPMs to produce a reasonable amount of power.

The gearbox ratio was calculated using the nominal values of the wind turbine and generator rotor speed. At a nominal wind speed of $14 \mathrm{~m} / \mathrm{s}$, the wind turbine hub rotational speed is 9.9 RPM while the rated rotor speed of the induction generator is 1510.5 RPM. The generator's rated output power is produced at the rated speed. The gearbox ratio is determined from the expression

$$
\varpi_{G R}=G \Phi_{T R}
$$

In the expression, $\mathrm{G}$ is the gearbox ratio, $\Phi_{\mathbf{G R}}$ and $\Phi_{\mathbf{T R}}$ are the rated angular rotor speed of the generator's rotor and the wind turbine. To calculate the value of the gearbox ratio, $\mathrm{G}$ was used as the subject of the above expression as follows: 
$>$ REPLACE THIS LINE WITH YOUR MANUSCRIPT ID NUMBER (DOUBLE-CLICK HERE TO EDIT) <

$$
G=\frac{\Phi_{G R}}{\Phi_{T R}}
$$

The nominal speed values for both the wind turbine hub and induction generator were substituted as follows:

$$
\begin{gathered}
G=\frac{1510.5 \mathrm{rpm}}{9.9 \mathrm{rpm}} \\
G=\frac{50.35 \pi \frac{\mathrm{rad}}{\mathrm{s}}}{1.036705 \frac{\mathrm{rad}}{\mathrm{sec}}} \\
G=152.5757576
\end{gathered}
$$

We also used another method to calculate the gearbox ratio by looking at the amount of torque required by the generator, in comparison with that produced by the turbine. The mechanical torque expression of the wind turbine is expressed as:

$$
T_{T}=\frac{P_{T}}{\varpi_{T R}}
$$

In the expression, $\mathrm{T}_{\mathrm{T}}$ and $\mathrm{P}_{\mathrm{T}}$ are the mechanical torque in Newton-meters (N.m), and power in megawatts (MW), produced by the wind turbine. The amount of torque required by the generator to produce a nominal power of $4 \mathrm{MW}$ is 25.671 $\mathrm{kN} . \mathrm{m}$, and the torque produced by the wind turbine is calculated as follows:

$$
\begin{gathered}
T_{T}=\frac{4 M W}{1.036705 \frac{\mathrm{rad}}{\mathrm{sec}}} \\
T_{T}=3.858378 \mathrm{MN} \cdot \mathrm{m}
\end{gathered}
$$

The mechanical torque transfer calculation was performed through the gearbox of the wind turbine using the principle defined by the expression:

$$
T_{G}=\frac{T_{T}}{G}
$$

In the above expression, $\mathrm{T}_{\mathrm{G}}$ is the generator torque. In addition, $\mathrm{G}$ is the subject of the formula, and the following expression is obtained:

$$
G=\frac{T_{T}}{T_{G}}
$$

The values of $3.858378 \mathrm{MN} . \mathrm{m}$ and $25.671 \mathrm{kN} . \mathrm{m}$ were then substituted in the variables $\mathrm{T}_{\mathrm{T}}$ and $\mathrm{T}_{\mathrm{G}}$ as follows:

$$
\begin{gathered}
G=\frac{3.858378 M N \cdot m}{25.671 k N . m} \\
G=152.5757576
\end{gathered}
$$

\begin{tabular}{|c|c|c|c|c|c|c|c|c|c|c|}
\hline \multicolumn{11}{|c|}{ Itds_windturbine.def } \\
\hline \multicolumn{3}{|c|}{ GENERATOR PARAMETERS } & \multicolumn{2}{|c|}{ MONITORING } & \multicolumn{2}{|c|}{ SIGNAL NAMES } & & & & \\
\hline \multicolumn{2}{|c|}{ CONFIGURATION } & \multicolumn{3}{|c|}{ TURBINE PARAMETERS } & \multicolumn{3}{|c|}{ Atmospheric Conditions } & \multicolumn{3}{|c|}{ Cp Constants } \\
\hline Name & & \multicolumn{2}{|c|}{ Description } & \multicolumn{2}{|r|}{ Value } & Unit & & in & Max & \\
\hline mva & \multicolumn{3}{|c|}{ Rated MVA of the Generator } & \multicolumn{2}{|c|}{4.842} & & & & & $\Delta$ \\
\hline freq & \multicolumn{3}{|c|}{ rated frequency of the Generator } & \multicolumn{2}{|c|}{50} & $\mathrm{~Hz}$ & & & & $\equiv$ \\
\hline \multirow[t]{2}{*}{ genrpm } & \multicolumn{3}{|c|}{ Generator rated rpm } & \multicolumn{2}{|c|}{1510.5} & $\mathrm{rev} / \mathrm{min}$ & 1 & & & $\Rightarrow$ \\
\hline & & & date & & & cel All & & & & \\
\hline
\end{tabular}

Fig. 3 shows the gearbox ratio and turbine rotor radius parameter settings.

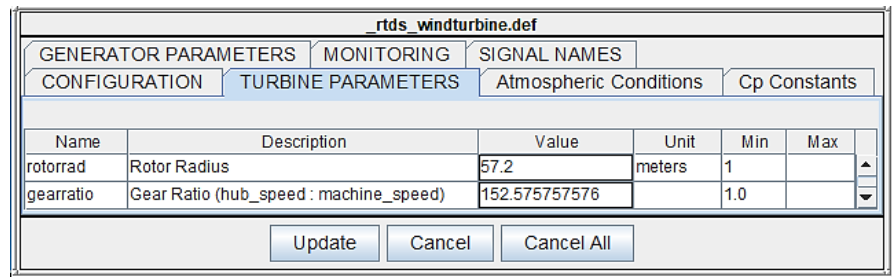

Fig. 3. Wind turbine rotor radius and gearbox ratio parameter settings

In addition to the wind turbine gearbox parameter settings and the rotor radius, the rated MVA, rated frequency, and rated RPM of the generator coupled to the wind turbine were set as shown in Fig. 4.

Fig. 4. Wind turbine generator rated apparent power (MVA), frequency, and rotor speed (RPM)

The standard operating temperature range for the wind turbine considered in this study was $-20^{\circ} \mathrm{C}$ to $45^{\circ} \mathrm{C}$. A decision is made on the default temperature value of $25^{\circ} \mathrm{C}$, where the wind turbine is assumed to produce a nominal power of 4/4.2 MW. The default setting value is shown in Fig. 5, with that of the default barometric pressure and percentage humidity.

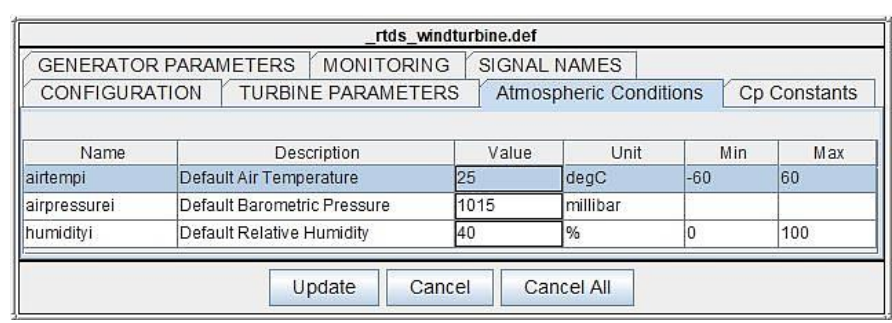

Fig. 5. Settings values for the default air temperature, barometric pressure, and relativity

Certain quantities are monitored, and their runtime availability depends on the settings performed during the modeling. The following section presents the modeling of wind turbine control, monitoring, and calculation logic.

3) Modeling of Wind Turbine Control, Monitoring, and Calculation Logic

The wind turbine model produces the output per unit torque or high-speed rotation based on the two principal input signals, pitch angle control adjustment, and wind speed. The control logic for these inputs is shown in Fig. 6. 


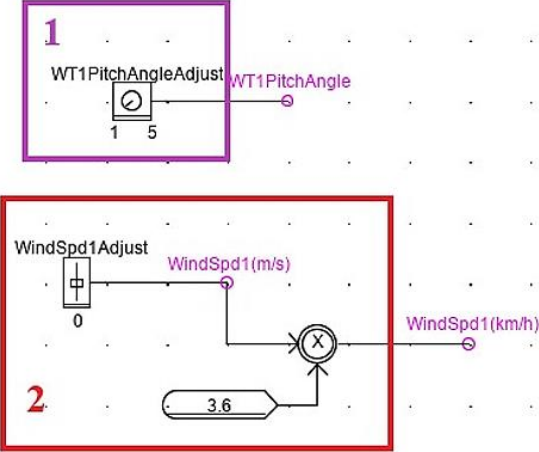

Fig. 6. Wind turbine generator blades pitch angle and wind speed adjustment and calculation logics

The wind speed range specified in the given wind turbine specifications is in meters per second $(\mathrm{m} / \mathrm{s})$, and the wind speed input signal to the turbine model provided is required in kilometers per hour $(\mathrm{km} / \mathrm{h})$. It is more precise to monitor and tune the wind speed in meters per second. A logic is developed, and its adjustments are in $\mathrm{m} / \mathrm{s}$, while the output is in units $(\mathrm{km} / \mathrm{h})$ required by the wind turbine.

The equation is derived for this function and its mathematical expression is

$$
x=3.6\left(v_{W}\right)
$$

where $\mathrm{x}$ represents the wind speed in $\mathrm{km} / \mathrm{h}$, and $v_{W}$ is the wind speed in $\mathrm{m} / \mathrm{s}$. The component with $X$ is the multiplier, and the component labeled WindSpdlAdjust is the slider for tuning the wind speed range.

The output from the slider is labeled $\operatorname{Wind} \operatorname{Spd} 1(\mathrm{~m} / \mathrm{s})$ and multiplies with a constant number 3.6, as shown in Fig. 6. The output labeled $\operatorname{Wind} \operatorname{Spd} 1(\mathrm{~km} / \mathrm{h})$ is a signal name that signally connects the output of the logic to the wind speed input on the wind turbine.

In the same figure, Zone 1 shows the dial selector switch for the selection of the angle at which the turbine blades are facing the wind, with its output signal named WTlPitchAngle. The logic used to perform this calculation is shown in zone 2 of Fig. 6.

The wind speed range is specified from $3 \mathrm{~m} / \mathrm{s}$ to $25 \mathrm{~m} / \mathrm{s}$, therefore, the slider is set such that the adjustment is made from $0 \mathrm{~m} / \mathrm{s}$ to $50 \mathrm{~m} / \mathrm{s}$ for evaluation purposes. The input parameter settings for the WindSpd1Adjust slider are shown in Fig. 7.

\begin{tabular}{|c|c|c|c|c|c|}
\hline \multicolumn{6}{|c|}{ Itds_sharc_ctl_SLIDER } \\
\hline \multicolumn{6}{|c|}{ Parameters } \\
\hline Name & Description & Value & Unit & Min & Max \\
\hline Name & Slider Name & WindSpd1Adjust & & & \\
\hline Init & Initial Value & 0 & & & \\
\hline Max & Maximum Value & 50 & & & \\
\hline Min & Minimum Value & 0 & & & \\
\hline \multirow[t]{2}{*}{ Units } & Units & $m / s$ & & & \\
\hline & & Cancel & All & & \\
\hline
\end{tabular}

Fig. 7. Wind speed adjustment settings

The pitch angle adjustment of a wind turbine is not as simple as the punching values in degrees (of rotation). Various parameters are considered when modeling a controller for this feature. Because of the time that would be spent in designing a controller for this purpose, as well as the theory to be undergone for more understanding about controllers, the study uses a dial selector switch for this feature, whose application does not affect the emphasis of the study. The configuration settings of the dial selector switch are shown in Fig. 8.

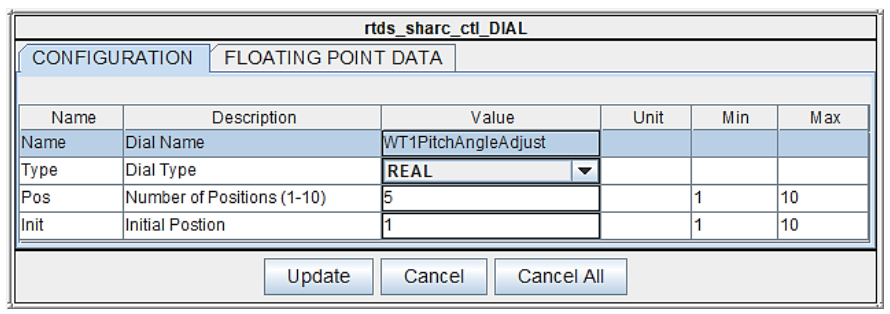

Fig. 8. Wind turbine blade pitch angle adjustment slider settings

In the above figure, the number of positions is set to five, each position specifying the value of the pitch angle $(\beta)$, and the settings for these positions are shown in Fig. 9.

\begin{tabular}{|c|c|c|c|c|c|}
\hline \multicolumn{6}{|c|}{ itds_sharc_ctl_SLIDER } \\
\hline \multicolumn{6}{|l|}{ Parameters } \\
\hline Name & Description & Value & Unit & Min & Max \\
\hline Name & Slider Name & WindSpd1Adjust & & & \\
\hline Init & Initial Value & 0 & & & \\
\hline Max & Maximum Value & 50 & & & \\
\hline Min & Minimum Value & 0 & & & \\
\hline Units & Units & $\mathrm{m} / \mathrm{s}$ & & & \\
\hline & & Cancel & All & & \\
\hline
\end{tabular}

Fig. 9. Wind speed adjustment settings

The wind speed operating range of the Vestas V117-4.2 MW wind turbine is specified from $3 \mathrm{~m} / \mathrm{s}$ to $25 \mathrm{~m} / \mathrm{s}$. In addition, the rotational (angular) speed of the turbine rotor is specified in relation to the wind speed range, and the data are listed in Table I.

The tip speed ratio is calculated from a rad/s value, the turbine rotor speed was converted from RPM to $\mathrm{rad} / \mathrm{s}$, and the values are shown in the third column of the table above. The two parameters influence the turbine efficiency $(C p), \beta$ and $\lambda$.

TABLE I

WIND SPEED AND THE ANGULAR SPEED OF THE WIND TURBINE ROTOR

\begin{tabular}{lll}
\hline \hline $\begin{array}{l}\text { Wind } \\
\text { Speed }\end{array}$ & $\begin{array}{l}\text { Wind turbine rotor angular } \\
\text { speed (RPM) }\end{array}$ & $\begin{array}{l}\text { Wind turbine rotor } \\
\text { angular speed (rad/sec) }\end{array}$ \\
\hline 3 & 2.1 & 0.219911 \\
14 & 9.9 & 1.036705 \\
23 & - & - \\
25 & 17.6 & 1.843068 \\
\hline \hline
\end{tabular}

The $C p$ values were determined for each tip speed ratio with different pitch angle adjustments, and the results are shown in Table II. 
$>$ REPLACE THIS LINE WITH YOUR MANUSCRIPT ID NUMBER (DOUBLE-CLICK HERE TO EDIT) <

TABLE II

WIND SPEED AND THE ANGULAR SPEED OF THE WIND TURBINE ROTOR BASED ON THE 32 DEGREES PITCH ANGLE ADJUSTMENT

\begin{tabular}{lllll}
\hline \hline $\mathrm{V}_{\mathrm{W}}$ & $C p$ & $\omega_{\mathrm{H}}$ & $\lambda$ & $\beta$ \\
\hline 3 & 0.405892 & 0.219911 & 13 & 0 \\
14 & 0.375725 & 1.036705 & 13 & 5 \\
25 & 0.285222 & 1.843068 & 13 & 10 \\
36 & -0.07679 & 2.666666 & 13 & 20 \\
47 & -0.82978 & 3.48 & 13 & 32 \\
& & & \\
\hline \hline
\end{tabular}

The value of the tip speed ratio $(\lambda)$ is constant because the relationship between the increase in wind speed is directly proportional to the increase in the angular speed of the turbine rotor. The turbine coefficient $(C p)$ versus wind speed curve is plotted for this wind turbine, as shown in Fig. 10. This curve is plotted using different values of $\beta$ and $\lambda$. The graph obtained in the plot shows the maximum value of $C p$ at $0^{\circ}$ and it follows the same characteristics as those in the literature.

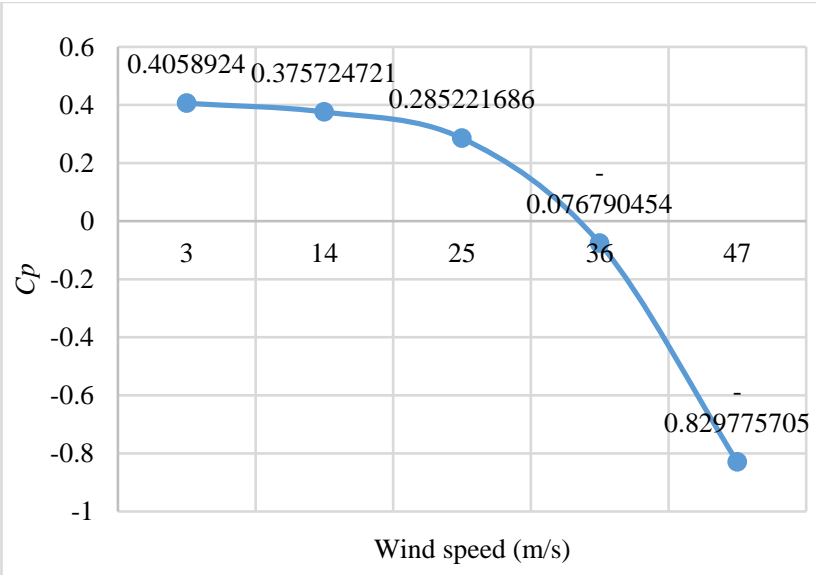

Fig. 10. Turbine power coefficient versus the wind speed at different pitch angle adjustments

The pitch angle controller controls the value of $C p$ to produce the rated power at multiple ranges of wind speed. When the wind speed increases and the pitch angle is 0.4 , the power produced by the wind turbine will be large. Tuning the value of $C p$ to a lesser value reduces the power output of the wind turbine. When the wind speed is low, the power will be reduced; therefore, tuning of $C p$ to a higher value increases the power output of the wind turbine.

However, the $C p$ versus the wind speed characteristic for a wind power plant presented in this paper may not be the same as that found in the literature. This is because of the absence of a pitch angle controller. In addition, the pitch angle controller does not affect the desired output power from the model.

\section{B. Induction Generator Model}

The power measured from the output of the wind turbine is the mechanical power and is transferred in the form of a perunit mechanical torque to the generator with which it is coupled. The generator selected for this study is a squirrel-cage induction generator because of its simplicity and low cost. Fig. 11 shows the induction generator model.

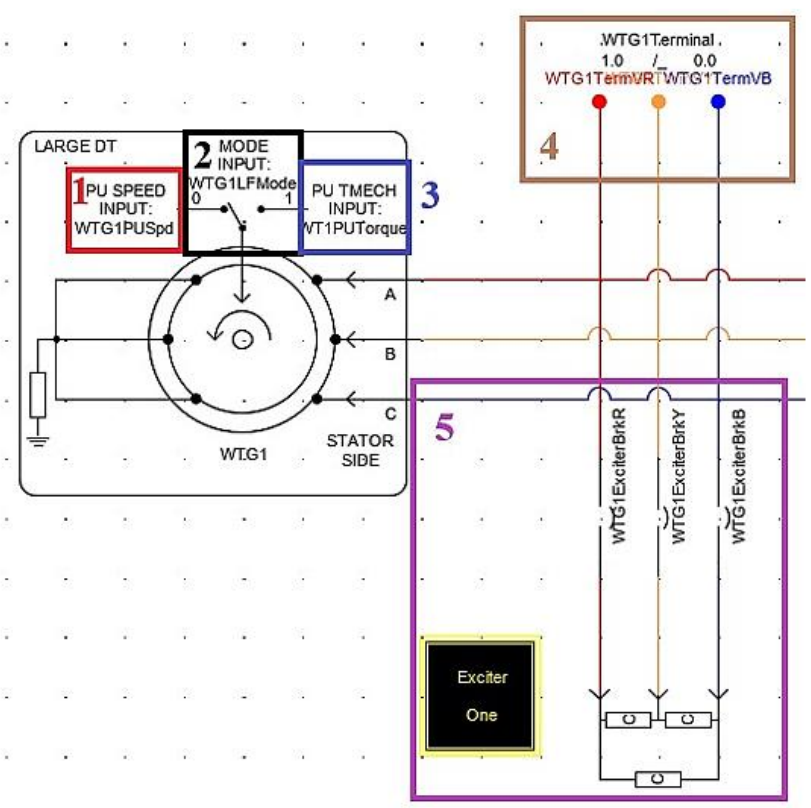

Fig. 11. Squirrel-cage induction generator model with the exciter circuit

The induction generator model in the figure has three input signals written and shown in zone 1 , zone 2 , and zone 3 as $P U$ SPEED INPUT, MODE INPUT, and PU TMECH INPUT. The two input signals are shown in Zone 1 and Zone 3 , and one is used, depending on the selected input signal, which is controlled by the input signal in Zone 2, which is the MODE input signal.

The circuit shown in Zone 5 of Fig. 11 is the exciter circuit and is connected to the stator terminals of the induction generator represented by a node in Zone 4 . This circuit assists in building up the stator terminal output voltage of the induction generator.

\section{1) Squirrel-Cage Induction Generator Modeling}

One of the most important settings in induction generator modeling is the definition of the motor electrical parameters, as shown in Fig. 12. The stator, rotor, and core resistance, and reactance parameters of this machine are entered in per-unit values. These values were calculated from the base values specified by the guide for the RSCAD induction generator model.

The following are the base values specified for calculating the per-unit values of the machine:

- Base voltage $\left(\mathrm{V}_{\mathrm{B}}\right)$ : Rated line-to-neutral stator voltage of the generator as the base value for the voltage

- Power: The rated MVA of the machine was used as the base value for the power

- Base current $\left(\mathrm{I}_{\mathrm{B}}\right)$ : The rated stator current of the machine is used as the base value for the current

- Base impedance $\left(Z_{B}\right)$ : The ratio of the base voltage 
$\left(V_{B}\right)$ to the base current $\left(I_{B}\right)$ is used as the base value for the base impedance

\begin{tabular}{|c|c|c|c|c|c|c|}
\hline \multicolumn{7}{|c|}{ If_rtds_risc_sld_INDM } \\
\hline \multicolumn{7}{|c|}{ ENABLE MONITORING IN RUNTIME SIGNAL NAMES FOR RUNTIME } \\
\hline \multicolumn{4}{|c|}{ MACHINE SATURATION CURVE BY FACTORS } & \multicolumn{3}{|c|}{ MONITORING OPTIONS } \\
\hline \multicolumn{3}{|c|}{ MOTOR ELECTRICAL PARAMETERS } & \multicolumn{4}{|c|}{ MECHANICAL PARAMETERS } \\
\hline \multicolumn{2}{|c|}{ INITIAL CONDITIONS } & LOAD FLOW & \multicolumn{4}{|c|}{ CONTROLS COMPILER INPUT } \\
\hline \multicolumn{3}{|c|}{ INDUCTION MACHINE CONFIGURATION } & \multicolumn{4}{|c|}{ PROCESSOR ASSIGNMENT } \\
\hline Name & \multicolumn{2}{|c|}{ Description } & Value & Unit & Min & Max \\
\hline vbsil & Rated Stator Voltag & -LRMS ) & 4 & $\mathrm{kV}$ & 0.01 & \\
\hline trato & \multicolumn{2}{|c|}{ Turns Ratio, Rotor over Stator } & 1.0 & p.u. & 0.01 & \\
\hline pbase & \multicolumn{2}{|l|}{ Rated MVA } & 4.842 & JMVA & 0.0001 & \\
\hline hitz & \multicolumn{2}{|l|}{ Rated Frequency } & 50 & Hert & 5.0 & 150.0 \\
\hline ra & \multicolumn{2}{|l|}{ Stator Resistance } & 0.0067 & p.u. & 0.002 & \\
\hline$x a$ & \multicolumn{2}{|c|}{ Stator Leakage Reactance } & 0.1615 & p.u. & 0.03 & \\
\hline $\mathrm{xmd0}$ & \multicolumn{2}{|c|}{ Unsaturated Magnetizing Reactance } & 3.1946 & p.u. & 0.75 & \\
\hline ifd & \multicolumn{2}{|c|}{ First Cage Rotor Resistance } & 0.0069 & p.u. & 0.003 & \\
\hline xfd & \multicolumn{2}{|c|}{ First Cage Rotor Leakage Reactance } & 0.1615 & p.u. & 0.003 & \\
\hline rkd & \multicolumn{2}{|c|}{ Second Cage Rotor Resistance } & 0.2 & p.u. & 0.003 & $1.0 \mathrm{e} 6$ \\
\hline $\mathrm{xkd}$ & \multicolumn{2}{|c|}{ Second Cage Rotor Leakage Reactance } & 0.07 & p.u. & 0.0 & $1.0 \mathrm{e} 6$ \\
\hline $\mathrm{xkf}$ & \multicolumn{2}{|c|}{ Rotor Mutual Leakage Reactance } & 0.0 & p.u. & 0.0 & $1.0 \mathrm{e} 6$ \\
\hline intrl & \multicolumn{2}{|l|}{ Neutral Resistance } & 0.0 & p.u. & 0.0 & \\
\hline xntrl & \multicolumn{2}{|l|}{ Neutral Reactance } & 0.0 & p.u. & & \\
\hline & & date & & & & \\
\hline
\end{tabular}

Fig. 12. Squirrel-cage induction generator model electrical parameter settings

Another setting is the inertia constant of the generator. As specified by its units, MWs/MVA, is calculated from the values provided in the generator specifications, and the value is set in the mechanical parameters as shown in Fig. 13 of the induction generator parameter settings.

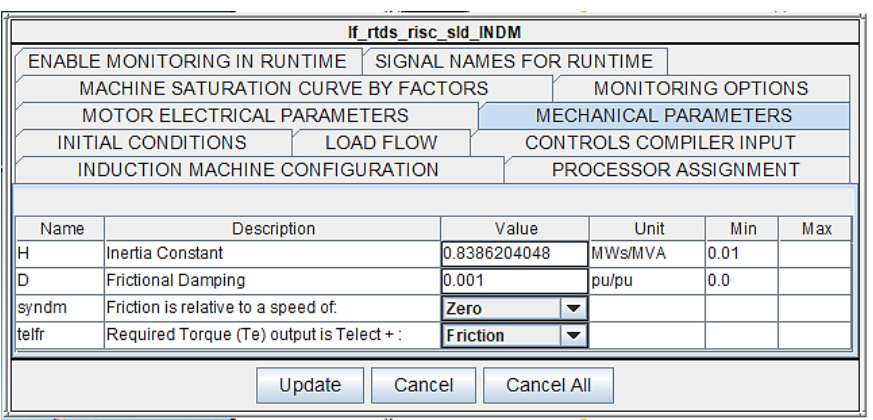

Fig. 13. Squirrel-cage induction generator model mechanical parameter settings

The induction generator produces electric power by converting mechanical power input to its shaft. The voltage at the generator's stator terminal will never build up even when the torque from the prime mover is sufficient. Therefore, an exciting circuit is required for the voltage build-up on the stator terminals of the induction generator. This circuit produces voltage from a small amount of current available at the stator terminals during the rotation of the rotor of the generator.

\section{2) Modeling of Squirrel-Cage Induction Generator Excitation} Circuit

The squirrel-cage induction generator rated values were used for this calculation. The apparent power (S) was calculated from the rated current and voltage of the induction generator using the following equation:

$$
\begin{gathered}
S=\sqrt{3} I V \\
S=\sqrt{3}(0.69888 \mathrm{~A})(4 \mathrm{kV}) \\
\quad S=4.84198 \mathrm{MVA}
\end{gathered}
$$

Induction machines draw a lagging current from the circuit, and their power factor is usually assumed to be 0.8 lagging. Therefore, the active power is calculated as follows:

$$
\begin{gathered}
P=4.84198 M V A(0.8261) \\
P=3.999999 M W
\end{gathered}
$$

The total reactive power required from the excitation circuit was calculated using the values of the active and apparent powers determined above. The equation

$$
Q_{T}=\sqrt{S^{2}-P^{2}}
$$

is used.

In the equation, $Q_{T}$ is the total reactive power of the excitation circuit, which is calculated as:

$$
\begin{gathered}
Q_{T}=\sqrt{(4.84198 M V A)^{2}-(3.99999 M W)^{2}} \\
Q_{T}=2.72853 M V A
\end{gathered}
$$

The value calculated here is the minimum reactive power required to excite the induction machine to produce a voltage at the stator terminals. For low cost, the combination of capacitors to produce $Q_{T}$ is usually connected in a delta connection. In this connection, the capacitive reactance is three times less than the total reactive power of the circuit. Therefore, the value of 0.909510 MVAr was determined for the excitation circuit model presented in this paper.

From this, we calculated the current flowing through each capacitor using the equation:

$$
I_{Q}=\frac{Q_{P}}{V_{\text {Phase }}}
$$

In the expression, $I_{Q}, Q_{P}$ and $V_{\text {Phase }}$ are the current flow in the reactive component, per-phase reactive power of the excitation circuit, and per-phase voltage, respectively. The voltage is equal to the line-to-line voltage because of the connection method of the reactive component. The reactive current was then calculated as follows:

$$
\begin{gathered}
I_{Q}=\frac{0.909510 \mathrm{MVAr}}{4 \mathrm{kV}} \\
I_{Q}=0.22738 \mathrm{kA}
\end{gathered}
$$

In addition, the capacitive reactance of the per-phase capacitor is determined using the equation: 
$>$ REPLACE THIS LINE WITH YOUR MANUSCRIPT ID NUMBER (DOUBLE-CLICK HERE TO EDIT) <

$$
X_{C}=\frac{V}{I_{Q}}
$$

In the equation, $\mathrm{X}_{\mathrm{C}}$ is the capacitive reactance for each capacitor and is calculated as

$$
\begin{aligned}
X_{C} & =\frac{4 k V}{0.22738 k A} \\
X_{C} & =17.591697 \Omega
\end{aligned}
$$

The setting parameters of the reactive power compensator device used in RSCAD were entered in the per-phase microFarads. The per-phase micro-Farads value for this circuit was determined using the expression

$$
C_{P}=\frac{1}{2 \pi f X_{C}}
$$

In the expression, $\mathrm{Cp}$ is the per-phase capacitance required for each capacitor to generate the minimum amount of the perphase reactive power, and $f$ is the rated frequency of the generator. The calculation was performed as follows:

$$
\begin{gathered}
C_{P}=\frac{1}{2 \pi(50)(17.591697)} \\
C_{P}=180.94325 u F
\end{gathered}
$$

$\mathrm{C}_{\mathrm{P}}$ is the amount of the per-phase capacitance that is connected to the induction generator stator terminals its excitation. Fig. 14 shows the parameter settings entered for the excitation circuit used for the induction generator.

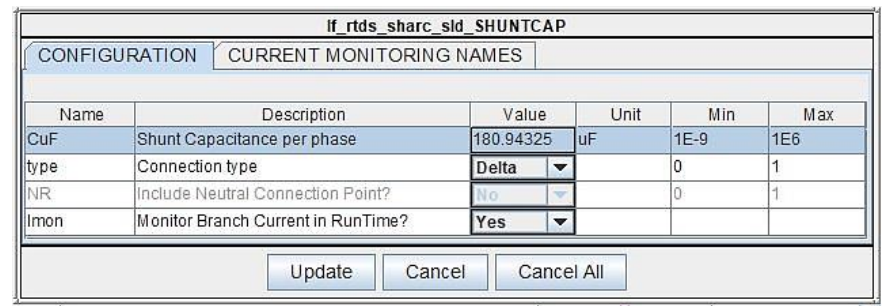

Fig. 14. Squirrel-cage induction generator model mechanical parameter settings

The value of the capacitance for the excitation circuit depends on the connected number of wind turbine generator units, and in this paper, we present no fixed capacitance value.

\section{3) Modeling of Squirrel-Cage Induction Generator Control,} Monitoring, and Calculation Logic

Relationship between wind speed and turbine rotor speed The rotor speed increased as the wind speed increased. Because of this relationship and the per-unit speed control input to the driven generator, a logic is designed to calculate the per-unit speed from the speed of the wind.

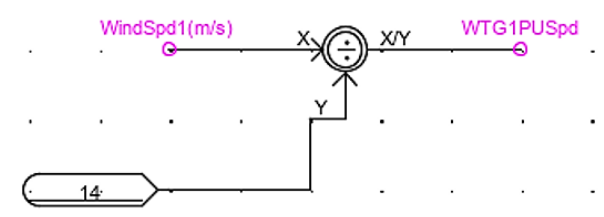

Fig. 15. Logic for wind turbine generator per-unit speed control

The nominal speed of the wind is $14 \mathrm{~m} / \mathrm{s}$, and the wind turbine is expected to produce a nominal power of $4 / 4.2 \mathrm{MW}$ at this speed. At a wind speed of $14 \mathrm{~m} / \mathrm{s}$, the speed input to the generator was expected to be 1 per unit. The logic was designed as shown in Fig. 15. In the figure, constant 14 is the rated wind speed in meters per second $(\mathrm{m} / \mathrm{s})$ and is used as the base value for obtaining the per-unit output signal. The designed logic uses the calculated per-unit speed of the wind and applies it to the generator.

The component with a division sign produces an output signal assigned to WTG1PUSpd. The signal WindSpedl $(\mathrm{m} / \mathrm{s})$ is the output from the wind input speed adjusting slider for the wind turbine. The WTGIPUSpd signal was connected to the generator as part of the control signal.

Three signal names were defined for the control of the induction generator, as shown in Fig. 16.

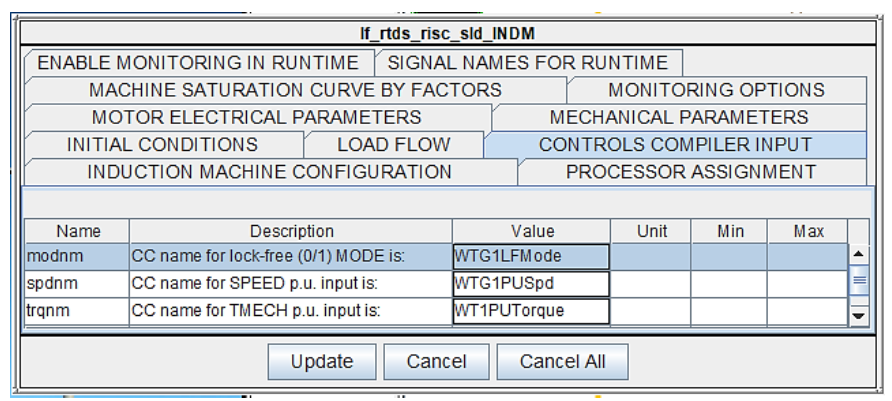

Fig. 16. Control's compiler settings for induction generator model

The signal WTGILFMode controls the mode of operation of the induction generator. When the lock/free switch (WTGILFSW) is placed in the free mode (OFF state), the generator operates using the input signal WTG1PUTorque and operates through the input signal WTGIPUSpd when the switch is positioned in the other way.

Another mapping of signals exists between the wind turbine and induction generator, namely, the per-unit feedback speed from the induction generator to the wind turbine. The input to the wind turbine was WTGIPUSpdd. This signal is made available by setting the parameters to monitor in the induction generator, as shown in Fig. 17.

Part of the signals monitored in the figure are the stator currents, electrical torque, rotor speed of the generator, output electrical real $(\mathrm{P})$, and reactive $(\mathrm{Q})$ power. Setting these quantities makes them available on runtime simulation cases for monitoring purposes. 
$>$ REPLACE THIS LINE WITH YOUR MANUSCRIPT ID NUMBER (DOUBLE-CLICK HERE TO EDIT) <

\begin{tabular}{|c|c|c|c|c|c|c|c|c|}
\hline \multicolumn{9}{|c|}{ If_rtds_risc_sld_INDM } \\
\hline \multicolumn{9}{|c|}{ ENABLE MONITORING IN RUNTIME } \\
\hline \multicolumn{5}{|c|}{ MACHINE SATURATION CURVE BY FACTORS } & \multicolumn{4}{|c|}{ MONITORING OPTIONS } \\
\hline \multicolumn{4}{|c|}{ MOTOR ELECTRICAL PARAMETERS } & \multicolumn{5}{|c|}{ MECHANICAL PARAMETERS } \\
\hline \multicolumn{4}{|c|}{ INITIAL CONDITIONS LOAD FLOW } & \multicolumn{5}{|c|}{ CONTROLS COMPILER INPUT } \\
\hline \multicolumn{4}{|c|}{ INDUCTION MACHINE CONFIGURATION } & \multicolumn{5}{|c|}{ PROCESSOR ASSIGNMENT } \\
\hline Name & \multicolumn{2}{|c|}{ Description } & \multicolumn{2}{|c|}{ Value } & Unit & Min & Max & \\
\hline nam1 & \multicolumn{2}{|c|}{ Name: A phase Stator I } & \multicolumn{2}{|l|}{ WTG1IR } & & 0 & 1 & $\Delta$ \\
\hline nam2 & \multicolumn{2}{|c|}{ Name: B phase Stator I } & \multicolumn{2}{|l|}{ WTG1IY } & & 0 & 1 & \\
\hline nam3 & \multicolumn{2}{|c|}{ Name: C phase Stator I } & \multicolumn{2}{|l|}{ WTG1IB } & & 0 & 1 & \\
\hline nam4 4 & \multicolumn{2}{|c|}{ Name: A phase Rotor I } & \multicolumn{2}{|l|}{ IROTA1 } & & 0 & 1 & \\
\hline nam5 & \multicolumn{2}{|c|}{ Name: B phase Rotor I } & \multicolumn{2}{|l|}{ IROTB1 } & & 0 & 1 & \\
\hline $\operatorname{nam6}$ & \multicolumn{2}{|c|}{ Name: $\mathrm{C}$ phase Rotor I } & \multicolumn{2}{|l|}{ IROTC1 } & & 0 & 1 & \\
\hline nam7 & \multicolumn{2}{|c|}{ Name: Rotor Angle, Radians } & \multicolumn{2}{|l|}{ ROTANG1 } & & 0 & 1 & \\
\hline nam8 & \multicolumn{2}{|c|}{ Name: Elect Torque, PU } & \multicolumn{2}{|c|}{ WTG1ElectTorque } & & 0 & 1 & \\
\hline nam9 & \multicolumn{2}{|c|}{ Name: Rotor Speed, PU } & \multicolumn{2}{|c|}{ WTG1PUSpdd } & & 0 & 1 & \\
\hline nam10 & \multicolumn{2}{|c|}{ Name: Stator $\mathrm{P}, \mathrm{MW}$} & \multicolumn{2}{|l|}{ WTG1P } & & 0 & 1 & \\
\hline \multirow[t]{2}{*}{ nam11 } & \multicolumn{2}{|c|}{ Name: Stator Q, MVAR } & \multicolumn{2}{|l|}{ WTG1Q } & & 0 & 1 & $\nabla$ \\
\hline & & date & Cancel & & & & & \\
\hline
\end{tabular}

Fig. 17. Signal names for runtime monitoring

The excitation circuit model for the induction generator model requires control, monitoring, and calculation logic. The logic used to perform these functions is shown in Fig. 18. In the figure, Zone 1 shows a switch for controlling the circuit breaker for switching the ON/OFF excitation circuit. Zone 2 shows the logic for calculating and monitoring reactive power produced by the excitation circuit. This logic determines the reactive power using the product of the RMS current and the voltage seen by the circuit.

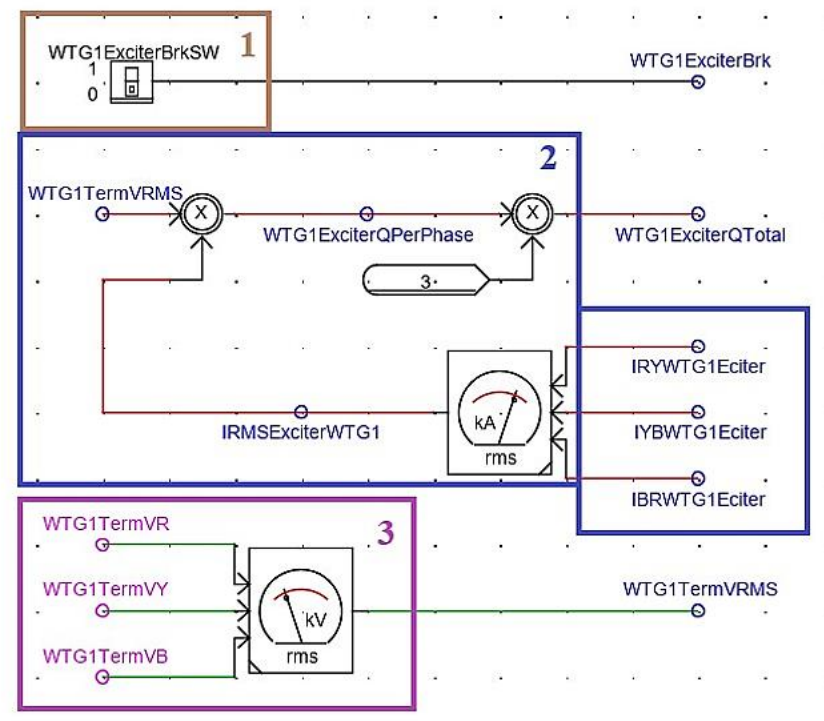

Fig. 18. Excitation circuit control, monitoring, and calculation logic

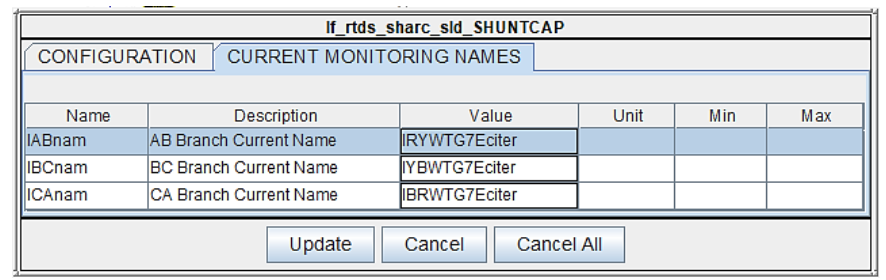

Fig. 19. Induction generator exciter phase current signal settings for the calculation and monitoring of reactive power, exciter current, and voltage
The signals named IRYWTGIEciter, IYBWTGIEciter, and IBRWTGIEciter shown in Zone 2 are the phase currents monitored from the exciter circuit. These signals are found in the settings of the capacitor bank model and are set for monitoring, as shown in Fig. 19.

\section{Wind Power Plant Power Transformer Modeling}

A complete wind power plant consists of power system components such as generator units, step-up transformers to step up the generated low-voltage to a medium voltage connected to the collector circuit, and medium voltage to highvoltage transformers for stepping up the voltage to a transmission level voltage [8].

The transformers of 5 MVA were selected for each wind turbine generator substation unit (WTGSU). Having looked at the WTGSU transformer capacity of 5 MVA, there were six of these transformers, and at full load, each delivered 5 MVA to the collector busbar. From the collector, a $24-230 \mathrm{kV}$ step-up transformer is required to deliver 18 times 5 MVA (equal to 90 MVA) to the transmission system through the transmission lines. Therefore, a 90 MVA transformer was selected.

With all the major components modeled, each wind turbine generator unit was connected to the collector busbar through WTGSUs (transformers) to complete the collector circuit.

Power-generating plants are usually located in remote areas, away from customers. Some studies specify that one of the advantages pertinent to wind power plants is that they provide clean power closer to the load.

Power was generated and transmitted to the required location. To achieve this, a transmission line must be modeled for a wind power plant to ensure that the power reaches the customers even in the remote area. In the case of the transmission system model used for this study, modeling is easier because the RSCAD model uses more than one subsystem. Transmission line models are used to interconnect two or more power-system circuits between subsystems.

\section{Wind Power Plant High-Voltage Transmission Line Modeling on RSCAD}

A $15 \mathrm{~km}$ transmission line model is used for this model, interconnecting the two systems, the transmission, and the wind power plant system under study.

The parameters used for this transmission line model were obtained from one of the RTDS tutorials, whose data were reliable and did not deviate from the aim of the study. The original line had a length of $100 \mathrm{~km}$ and was reduced to $15 \mathrm{~km}$. This is done to reduce power losses, while the purpose of a wind power plant model is kept realistic.

\section{E. Wind Power Plant Receiving-End Reactive Power Compensator Device Modeling}

A load demand of $15 \mathrm{MW}$ was considered in this study. Therefore, a WPP of at least 15 MW was modeled. Corresponding to the active power, the grid codes specify the power factor at the terminals of Category $\mathrm{C}$ renewable power plants at a value of 0.95 . The corresponding reactive power for this amount of active power at a power factor of 0.95 is 4.930261578 MVAr. This is the minimum value of the reactive power compensator device that must be connected at the receiving end terminal of the wind power plant to produce a 
$>$ REPLACE THIS LINE WITH YOUR MANUSCRIPT ID NUMBER (DOUBLE-CLICK HERE TO EDIT) <

power factor of 0.95 when the active power produced is 15 MW.

Reactive power compensator devices use capacitor banks. The capacitance of the capacitor bank was calculated using the expression:

$$
C_{P}=\frac{I_{Q}}{2 \pi f V_{P}}
$$

In the above expression, $\mathrm{I}_{\mathrm{Q}}$ and $\mathrm{V}_{\mathrm{Phase}}$ are the current flow in the reactive component and the per-phase voltage, which is equal to the line-to-line voltage because of the connection method of the reactive component.

The value of $\mathrm{I}_{Q}$ can be found by using the expression

$$
I_{Q}=\frac{Q_{P}}{V_{\text {Phase }}}
$$

In the above expression, $Q_{P}$ is the per-phase reactance of the capacitor bank.

The value of the current is then calculated as

$$
\begin{aligned}
I_{Q} & =\frac{1.643420526 \mathrm{MVAr}}{0.9(230 \mathrm{kV})} \\
I_{Q} & =0.07939229594 \mathrm{kA}
\end{aligned}
$$

Therefore,

$$
\begin{gathered}
C_{P}=\frac{0.07939229594 \mathrm{kA}}{2 \pi(50)(0.9 P U)(230 \mathrm{kV})} \\
C_{P}=0.1220838294 \mu \mathrm{F}
\end{gathered}
$$

Capacitor banks cause many transient currents in the power system, which may affect other power system components. The transients are reduced by sequential switching. In the case of sequential switching, capacitor banks are divided into units, which is very effective in reducing the transients.

\begin{tabular}{|c|c|c|c|c|c|c|}
\hline \multicolumn{7}{|c|}{ If_rtds_sharc_sId_SHUNTCAP } \\
\hline \multicolumn{2}{|c|}{ CONFIGURATION } & \multicolumn{2}{|c|}{ CURRENT MONITORING NAMES } & \multirow[b]{2}{*}{ Unit } & \multirow[b]{2}{*}{ Min } & \multirow[b]{2}{*}{ Max } \\
\hline Name & & Description & Value & & & \\
\hline IABnam & AB Bran & ch Current Name & IRYWTG7Eciter & & & \\
\hline IBCnam & BC Brar & ch Current Name & IYBWTG7Eciter & & & \\
\hline \multirow[t]{2}{*}{ ICAnam } & CA Brar & ch Current Name & IBRWTG7Eciter & & & \\
\hline & & Update & Cancel & & & \\
\hline
\end{tabular}

For the capacitor bank presented above, a decision is made that there are 14 units. Therefore, each unit is fourteen times less than $0.1220838294 \mu F$, which then gives $0.00872035286 \mu F$ capacitor bank. The parameter settings for each capacitor are shown in Fig. 20.

Fig. 20. WPP terminal reactive power compensator device model settings parameters

Only one unit is shown in this part, although all other units have the same settings menu, with different labeling of signals. Monitoring is also a requirement for a reactive power compensator. A relationship exists between the current, voltage, and reactive power produced by the capacitor bank.
Using this relationship, the total reactive power contribution can be monitored at the busbar where these capacitor bank units are connected. This logic is illustrated in Fig. 21.

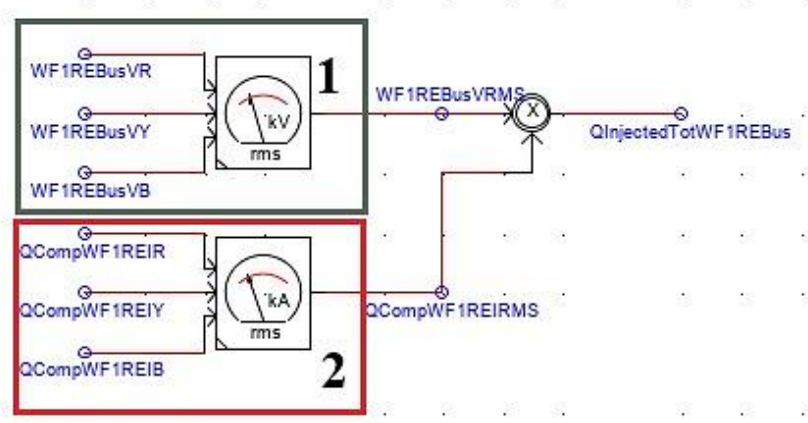

Fig. 21. Monitoring and calculation logic for reactive power injection device using the RMS voltage and current

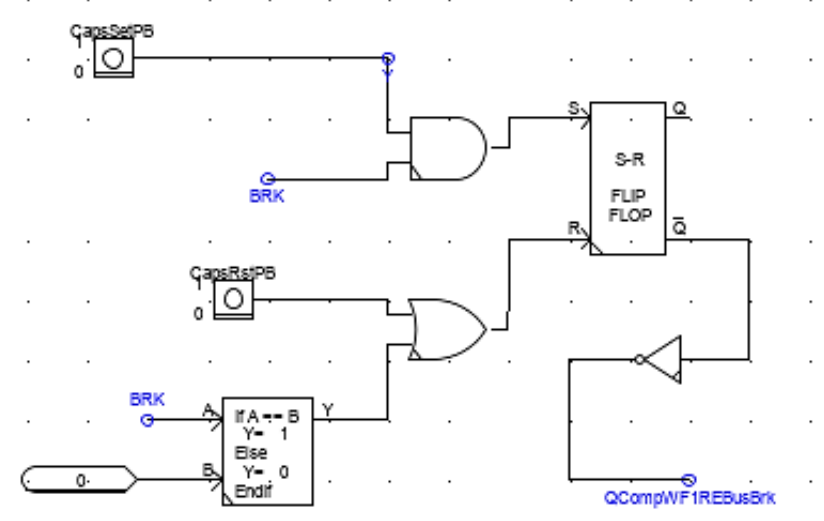

Fig. 22. Monitoring and calculation logic for reactive power injection device switching logic

In the figure, Zone 1 shows the logic for calculating the RMS voltage from the busbar at which the reactive power compensator devices are connected. In addition, in Zone 2, another RMS current calculator logic is shown, which monitors the total line current drawn by the active capacitor bank unit. The RMS output from both zones is multiplied, and the product gives the total reactive power injected.

The sequence switching of the capacitors for the reactive power compensator device was achieved using the logic shown in Fig. 22. A similar logic exists for the remaining capacitors.

\section{Wind Power Plant GRID CODE COMPLIANCE TEST}

In this test, the power flow was conducted, and the aerodynamic, mechanical, and electrical quantities were monitored. The operating temperature range for this wind turbine was from $-20^{\circ} \mathrm{C}$ to $45^{\circ} \mathrm{C}$, and the test was performed at a temperature of $25^{\circ} \mathrm{C}$.

The output power of the turbine may still be tuned to the desired output if the temperature is within the specified operating range. Humidity and air pressure also play a role in the values of $C p$ and are set to $30 \%$ and 1415 mbar, respectively. The mechanical and electrical quantities were monitored during the steady-state operation of the wind power 
$>$ REPLACE THIS LINE WITH YOUR MANUSCRIPT ID NUMBER (DOUBLE-CLICK HERE TO EDIT) <

plant, and at least one wind turbine generator unit is listed in Table III.

TABLE III

WIND TURBINE GENERATOR UNIT MONITORING AT STEADY-STATE POWER FlOW SiMULATION

\begin{tabular}{|c|c|c|c|}
\hline \multicolumn{2}{|c|}{ Mechanical quantities } & \multicolumn{2}{|l|}{ Electrical quantities } \\
\hline $\begin{array}{l}\text { Quantity } \\
\text { names }\end{array}$ & Values & Quantity names & Values \\
\hline Wind speed & $14 \mathrm{~m} / \mathrm{s}$ & $\begin{array}{l}\text { WTGSU primary } \\
\text { current }\end{array}$ & $0.01563 \mathrm{kA}$ \\
\hline Wind power & $23.31 \mathrm{MW}$ & $\begin{array}{l}\text { WTGSU secondary } \\
\text { current }\end{array}$ & $0.00130 \mathrm{kA}$ \\
\hline $\begin{array}{l}\text { Wind turbine } \\
C p\end{array}$ & 0.1718 & WTG electrical torque & $0.00986 \mathrm{PU}$ \\
\hline $\begin{array}{l}\text { Wind turbine } \\
\text { power }\end{array}$ & $4.003 \mathrm{MW}$ & WTG terminal voltage & $1.083 \mathrm{PU}$ \\
\hline $\begin{array}{l}\text { Wind turbine } \\
\text { rotor speed }\end{array}$ & 9.9 RPM & $\begin{array}{l}\text { WTG exciter reactive } \\
\text { power }\end{array}$ & $2.122 \mathrm{MVAr}$ \\
\hline \multirow[t]{3}{*}{$\begin{array}{l}\text { Wind turbine } \\
\text { torque }\end{array}$} & $\begin{array}{l}3.858 \\
\text { MN.m }\end{array}$ & $\begin{array}{l}\text { WTG active power }(\mathrm{P}) \\
\text { output }\end{array}$ & $0.02404 \mathrm{MW}$ \\
\hline & & $\begin{array}{l}\text { WTG reactive power } \\
\text { (Q) output }\end{array}$ & $-2.010 \mathrm{MVAr}$ \\
\hline & & $\begin{array}{l}\text { WTG reactive power } \\
\text { circuit current }\end{array}$ & $0.1633 \mathrm{kA}$ \\
\hline
\end{tabular}

The study assumes that all the WTGUs are synchronized; therefore, the results are the same for all units. The wind power plant receiving the end terminal is one of the most important points in a wind power plant. This is the point at which the grid code specifications are mostly referred to. Table IV shows the results of the monitored quantities at this point in the steadystate power flow.

TABLE IV

Wind Power Plant SEND-END AND RECEIVING-END MONitored VAlues at STEAdy-STATE POWER Flow

\begin{tabular}{lll}
\hline \hline Quantity names & $\begin{array}{l}\text { Actual } \\
\text { values }\end{array}$ & Per unit values \\
\hline Group 1 collector terminal voltage & $\begin{array}{l}26.02 \\
\mathrm{kV}\end{array}$ & $1.084 \mathrm{PU}$ \\
& $\begin{array}{l}249.9 \\
\mathrm{kV}\end{array}$ & $1.086 \mathrm{PU}$ \\
Wind farm sending-end bus voltage & 249.9 & $1.086 \mathrm{PU}$ \\
Wind farm receiving-end bus voltage & $\mathrm{kV}$ \\
$50 \mathrm{~Hz}$ & - \\
Wind farm sending-end frequency & $\begin{array}{l}50 \mathrm{~Hz} \\
\text { Wind farm receiving-end frequency }\end{array}$ & - \\
\hline \hline
\end{tabular}

The grid codes specify the continuous operating per-unit voltage level for Category $\mathrm{C}$ renewable power plants as 0.9 (minimum) to 1.0985 (maximum). As can be seen in the above table, under normal load flow conditions, the voltage measured on the high-voltage busbar of the modeled wind power plant is 1.086 per unit, which is acceptable.

The operating frequency of a renewable power plant is another quantity specified by grid codes. It is stated that the renewable power plant can be allowed to run continuously in the frequency range of $49-51 \mathrm{~Hz}$. The frequency of the modeled wind power plant does not violate the continuous operating range specified by the grid codes, as it is at $50 \mathrm{~Hz}$ under normal operating conditions.

\section{CONCLUSION}

This paper focuses on the modeling of a wind power plant (WPP). The real-time load flow simulation of the wind power plant was performed with the aim of the grid compliance test. In the test, the mechanical and electrical quantities were monitored while the wind power plant was operated at a steady state. In terms of the grid compliance test, the electrical quantities are monitored at the sending and receiving end terminals, because the wind power plant model consists of a transmission line system. The results show that the wind power plant operation complies with the grid codes.

\section{REFERENCES}

[1] F. International, "Forecast International's Energy Portal,"

Renewable Energy, 2020. .

[2] M. Rekik, A. Abdelkafi, and L. Krichen, "Synchronization of wind farm power system to utility grid under voltage and frequency variations," Int. J. Renew. Energy Res., vol. 5, no. 1, pp. 70-81, 2015, doi: 10.20508/ijrer.10547.

[3] V. Rana, R. Gupta, and N. Kumar, "Integration of Wind Farm into A Weak Distribution Network," vol. 4, no. 1, pp. 404-409, 2014.

[4] O. Hasnaoui and M. Allagui, "Dynamic performance improvement of wind farms equipped with three SCIG generators using STATCOM," J. Energy South. Africa, vol. 25, no. 4, pp. 128-135, 2014.

[5] S. Niwas, S. Singh, J. Ostergaard, and N. Jain, "Distributed Generation in Power Systems: An Overview and Key Issues," Citation, 2009, [Online]. Available:

http://orbit.dtu.dk/files/5202512/24IEC_paper.pdf.

[6] B. Wu, Y. Lang, and N. Zaragari, "Power Conversion and Control of Wind Energy Systems: Appendix B: Generator parameters," in Wind Energy, 2011, pp. 319-326.

[7] Vestas, "4 MW Wind Platform," Brocher, 2017.

[8] G. Jose and R. Chacko, "A review on wind turbine transformers," 2014 Апnи. Int. Conf. Emerg. Res. Areas Magn. Mach. Drives, AICERA/iCMMD 2014 - Proc., 2014, doi: 10.1109/AICERA.2014.6908172.

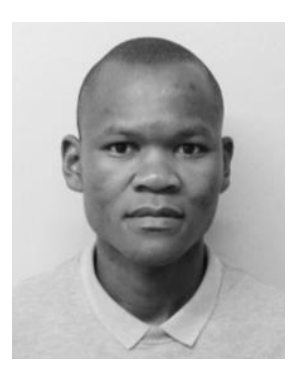

S. Nomandela was born in Ngqeleni village, Eastern Cape, South Africa. He received the N.Dip, B.Tech, and M.Eng degrees in Electrical Engineering, Power Systems from the Cape Peninsula University of Technology (CPUT), Cape Town in 2016, 2018, and 2021 respectively. From 2018 till 2020, he was a Graduate Research/Student Assistant with the Center for Substation Automation and Energy Management Systems (CSAEMS), and at present, he is a Junior Lecturer at the same university. His research interests are based on the role of wind power plants in grid networks, power system stability, protection, and communication networks. 